\title{
Evidence for a circannual rhythm of reproduction and prolactin secretion in a seasonally breeding macropodid marsupial, the Bennett's wallaby (Macropus rufogriseus rufogriseus)
}

\author{
B. R. Brinklow and A. S. I. Loudon \\ Institute of Zoology, Regent's Park, London NW1 4RY, UK
}

\begin{abstract}
Two groups of adult female wallabies were maintained in photoperiod-controlled rooms from June 1987 until August 1988. Group SSH was held on summer solstice photoperiods throughout the experiment; group $\mathrm{SN}$ was subjected to weekly stepwise simulated natural changes in photoperiod. Plasma melatonin concentrations reflected photoperiod with high concentrations during the dark phase in both groups. Group SN wallabies commenced oestrous cyclicity on 21 July ( \pm 19 days, $n=6$ ) entered reproductive quiescence on 14 February ( \pm 10 days, $n=5$ ) and recommenced cycling on 8 June ( \pm 3 days, $n=4)$. Group SSH wallabies began cycling on 27 July ( \pm 9 days, $n=7$ ) at a time that was not significantly different from that of group SN. Three out of five of group SSH exhibited a spontaneous period of reproductive quiescence of between 59 and 70 days commencing between 3 December and 25 February. There was a highly significant difference between the transient plasma prolactin response to a dopamine antagonist during cycling and quiescent periods in both groups $(P<0.001)$ such that the response was increased during periods of quiescence. Our data support the hypothesis that prolactin is involved in the control of seasonal quiescence in the female Bennett's wallaby and demonstrate that spontaneous changes in reproductive state and prolactin can occur when animals are maintained on unchanging long photoperiods.
\end{abstract}

\section{Introduction}

In some temperate zone mammals that breed for two or more years, seasonality of reproduction appears to be regulated by an endogenous circannual rhythm of reproduction, cued by seasonal changes in photoperiod. This has been extensively documented in both domestic sheep and sciurid rodents; in these animals changes in reproductive state have been shown to occur in the face of an unchanging photoperiod signal (e.g. Howles et al., 1982; Karsch et al., 1989; and see Davis, 1976).

Among macropodid marsupials, the females of two species exhibit photoperiodically regulated seasonality of reproduction, the tammar (Macropus eugenii) and Bennett's wallaby (Macropus rufogriseus rufogriseus). In these species the breeding season, during which unmated females exhibit repeated oestrous cycles, commences shortly after the summer solstice and terminates 2-6 weeks after the winter solstice (Andrewartha and Barker, 1969: tammar; Catt, 1977; Fleming et al., 1983; Curlewis et al., 1986; Loudon and Brinklow, 1990: Bennett's wallaby). Timing of the onset and termination of the breeding season can be manipulated by artificial changes in photoperiod (Curlewis $e t$ al., 1987; Curlewis and Loudon, 1989; Loudon and Curlewis, 1987; Brinklow and Loudon, 1989; Loudon and Curlewis, 1989).

Pituitary LH secretion is not directly seasonally modulated by oestradiol feedback in seasonally breeding wallabies, as it is

Revised manuscript received 23 December 1992. in eutherian mammals (Goodman and Karsch, 1981). Oestrous cycling is controlled primarily at the level of the ovarian corpus luteum (Hearn, 1974; Horn et al., 1985) which is held in a quiescent state under the influence of suckling or season (Berger 1966; Catt 1977; Renfree 1979; Flint and Renfree, 1982; Curlewis et al., 1987; Curlewis and Loudon, 1988a). The quiescent corpus luteum inhibits ovarian follicular development (Renfree et al., 1982) and, as a result of low progesterone production, an unimplanted blastocyst is held in diapause (Berger and Sharman, 1969).

There is ample evidence that pituitary prolactin, under the inhibitory control of dopamine, is responsible for maintaining the corpus luteum in lactational quiescence (Tyndale Biscoe and Hinds 1984; Curlewis et al., 1986; Curlewis and Loudon 1988a). The role of prolactin in the control of seasonal quiescence is less clear. Prolactin administration blocks luteal reactivation following reduction in photoperiod or hypophysectomy (Tyndale Biscoe and Hawkins, 1977; Brinklow and Loudon, 1989; Hinds, 1989). Administration of a single $5 \mathrm{mg} \mathrm{kg}^{-1}$ dose of the dopamine agonist bromocriptine terminates lactational quiescence (Tyndale Biscoe and Hinds 1984; Curlewis and Loudon 1988a). However, in early seasonal quiescence animals are less sensitive to bromocriptine, with only a proportion exhibiting luteal reactivation, and requiring extended treatment (TyndaleBiscoe $e$ al., 1986). Hinds (1989) demonstrated that reactivation of the corpus luteum in seasonal quiescence after bromocriptine treatment occurred only in animals in which the morning 
prolactin peak was suppressed. Later in seasonal quiescence bromocriptine administration does not cause luteal reactivation (Tyndale Biscoe and Hinds 1984; Curlewis et al., 1986) even with extended treatment (Brinklow and Loudon, 1989).

The present study was designed to test the hypothesis that there is an endogenous circannual rhythm of prolactin secretion and reproduction in Bennett's wallaby which persists under constant photoperiod conditions.

\section{Materials and Methods}

\section{Animals}

Sexually mature female Bennett's wallabies were obtained from the Institute's breeding colony at Whipsnade Park, Bedfordshire, UK. The animals were housed in photoperiodcontrolled light-proof rooms with access to an outside enclosure during the hours of daylight. Animals were maintained with ad libitum access to dried grass pellets, hay and water. Details of husbandry, collection of blood samples and levels of artificial illumination were as described by Curlewis et al. (1986) and Loudon and Curlewis (1987).

\section{Experimental treatments}

Two groups of animals were maintained as above from June 1987 until August 1988. Group SSH $(n=7)$ was held on summer solstice photoperiods from 18 June throughout the experiment (18.25 light: 5.75 dark; lights on at 03:00 and off at 21:15 GMT). Group SN ( $n=6)$ was subjected to a stepwise simulated natural photoperiod changed weekly beginning on 22 June. Photoperiods were calculated using Greenwich Royal Observatory Tables and civil twilight was added to the duration of daylength as described by Loudon and Curlewis (1987). Animals exhibiting weight loss of greater than $4 \mathrm{~kg}$ were removed from the study.

\section{Collection of blood samples and the prolactin response to domperidone}

Blood samples were collected twice a week throughout the experiment for monitoring oestrous cycles by plasma progesterone determination, as described by Curlewis et al. (1986) and Brinklow and Loudon (1989). Plasma was separated after centrifugation $\left(10 \mathrm{~min}\right.$ at $1000 \mathrm{~g}$ ) and stored at $-20^{\circ} \mathrm{C}$ until assayed. Tonic concentrations of prolactin determined using the heterologous radioimmunoassay detailed below do not exhibit a seasonal change in non-lactating female wallabies. The dopaminergic control of prolactin secretion throughout the experiment was investigated at intervals of approximately 4 weeks by determining the response to $1 \mathrm{mg}$ dopamine antagonist domperidone (Motilium: Janssens Pharmaceuticals, Grove, Oxon) as described by Brinklow and Loudon (1989) and PearceKelly et al. (1992). This response was determined as the net increase in plasma prolactin $30 \mathrm{~min}$ after a subcutaneous domperidone injection corrected for any difference after a saline control injection in a crossover design, with treatments and controls two days apart. Animals within groups were allocated equally and randomly to either domperidone or saline treatments for each determination.

Blood samples were taken for melatonin determination every $2 \mathrm{~h}$ for $24 \mathrm{~h}$ on 14 December 1987.

\section{Hormone assays}

Progesterone was determined in $n$-hexane extracts of plasma by the double antibody radioimmunoassay described by Curlewis et al. (1987). The limit of detection of the assay (zero minus $2 \mathrm{SD}$ ) was less than the lowest standard concentration of $20 \mathrm{pg} \mathrm{ml}^{-1}$ plasma. The intra-assay coefficients of variation were $4.8 \%$ and $6.7 \%$ at 188 and $708 \mathrm{pg} \mathrm{ml}^{-1}$, respectively, and the interassay coefficients of variation were $13.6 \%$ and $11.2 \%$ at 254 and $486 \mathrm{pg} \mathrm{ml}^{-1}$, respectively.

Plasma prolactin concentrations were measured using a double antibody radioimmunoassay with the guinea-pig antihuman serum (33-1-8) of McNeilly and Friesen (1978) validated for the wallaby by Curlewis et al. (1986). The samples were assayed against standard ovine prolactin (NIADDK PRL-S15) using iodinated tracer from the same batch. The limit of detection of the assay was less than the lowest standard concentration of $0.78 \mathrm{ng} \mathrm{ml}^{-1}$ plasma. The intra-assay coefficients of variation were 1.6 and $3.8 \%$ at 3.1 and $12.4 \mathrm{ng} \mathrm{ml}^{-1}$, respectively, and the interassay coefficients of variation were 19.8 and $8.4 \%$ at 2.6 and $17.7 \mathrm{ng} \mathrm{ml}^{-1}$, respectively.

Plasma melatonin concentrations were determined by direct radioimmunoassay using the method of Webley et al. (1985) validated for the wallaby by Curlewis and Loudon (1988b). The limit of detection of the assay was $5 \mathrm{pg} \mathrm{ml}^{-1}$ plasma. The intraassay coefficients of variation were 19.5 and $4.1 \%$ at 9 and $23 \mathrm{pg} \mathrm{ml}^{-1}$, respectively, and the interassay coefficients of variation were 21.5 and $16.3 \%$ at 7.5 and $25 \mathrm{pg} \mathrm{ml}^{-1}$, respectively.

\section{Statistical analysis}

Two consecutive plasma progesterone concentrations of $>300 \mathrm{pg} \mathrm{ml}^{-1}$ were considered to be indicative of an active corpus luteum (Curlewis et al., 1987). Animals were considered to be in quiescence if more than five consecutive samples prior to the beginning of a cycle had progesterone concentrations of $<300 \mathrm{pg} \mathrm{ml}^{-1}$.

The effects of treatment on prolactin response to domperidone were analysed by two-way analysis of variance (ANOVA) with repeated measures and comparisons within treatments by Duncan's multiple range test as previously described (Brinklow and Loudon, 1989) using SAS (Helwig and Council, 1979) which accounts for missing values. The comparison of oestrous cycling and prolactin response was, after confirmation of homogeneity of variances, analysed by multiple ANOVA using CSS (StatSoft Inc. Tulsa).

\section{Results}

All the animals in the experiment exhibited oestrous cyclicity by 11 August (as defined by a consistent rise in plasma progesterone concentration, Fig. 1). There was no significant difference in mean date of commencement of cycling between the 


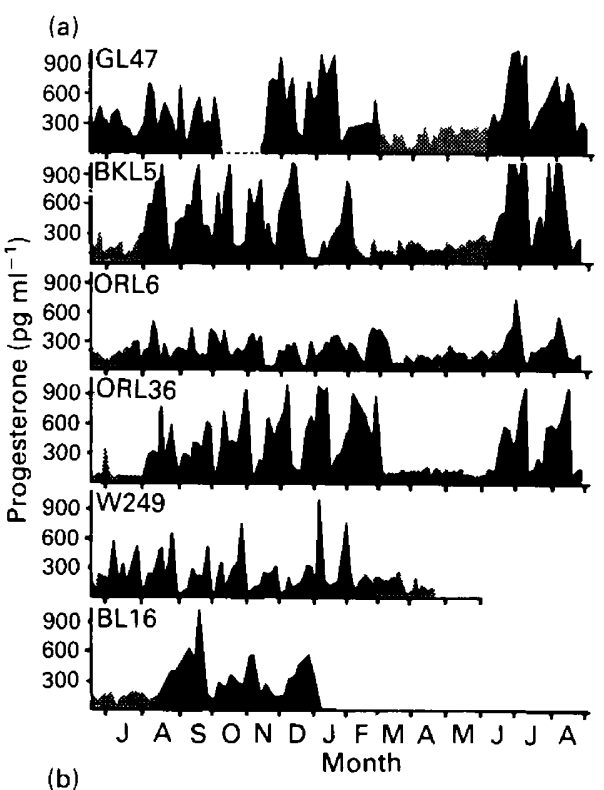

(b)
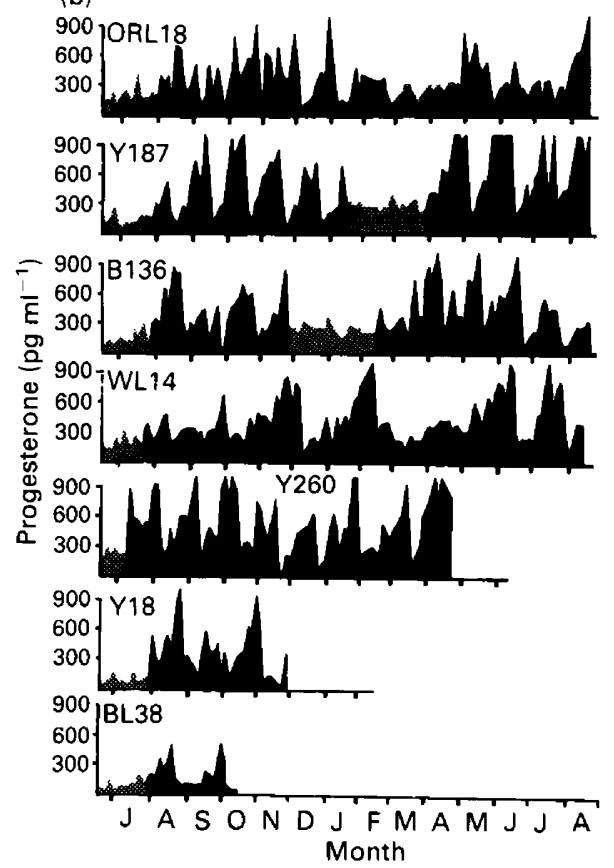

Fig. 1. Concentrations of progesterone in plasma of animals held on (a) simulated natural (SN) and (b) summer solstice (SSH) photoperiods throughout the study. Periods of reproductive quiescence are indicated by stippled areas. There are no data for wallaby GL47 between 21 October and 16 November owing to a period of clinical treatment.

groups (group SN 21 July \pm 19 days $(n=6)$ ), mean duration of photoperiod $17.2 \pm 0.3 \mathrm{~h}$; group SSH 27 July \pm 9 days $(n=$ 7 ), mean duration of photoperiod $17.17 \pm 0.06 \mathrm{~h}$ ). One animal in group SN (GL47) was cycling at the commencement of sampling and this date (I5 June) was taken as the start of her breeding season. No samples were taken from this animal between 21 October and 16 November due to a period of veterinary treatment.

In group $\mathrm{SN}$, animals entered quiescence (defined as the end of the last luteal phase of the breeding season) on 14

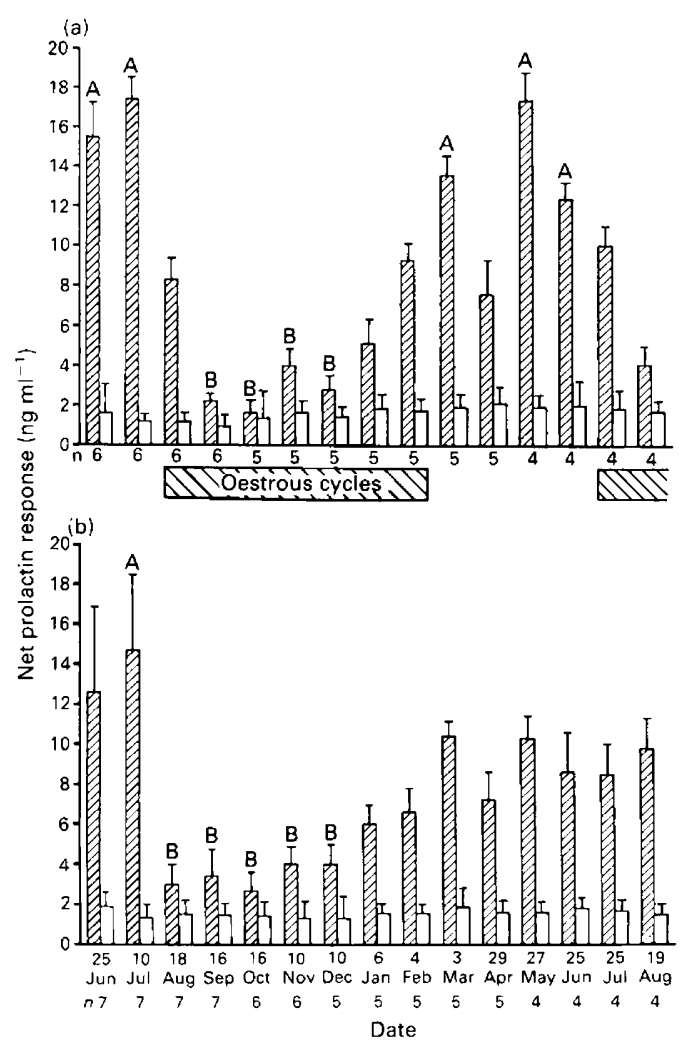

Fig. 2. Mean ( $\pm S E M)$ net prolactin response to domperidone after $30 \mathrm{~min}(\mathrm{~V})$ in animals held on (a) simulated natural (SN) and (b) summer solstice hold (SSH) photoperiods; preinjection values ( $\square$ ). Columns with different letters indicate values which are significantly different within treatments at $P<0.05$ (Duncan's multiple range test following one-way ANOVA for repeated measures). The period of the breeding season during which animals in group $\mathrm{SN}$ underwent repeated oestrous cycles is shown by the horizontal bar (因); $n=$ number of animals in each group.

February \pm 10 days $(n=5)$ at a photoperiod $11.1 \pm 0.2 \mathrm{~h}$ and recommenced cycling on 8 June \pm 3 days $(n=4)$ at a photoperiod of $18.1 \pm 0.07 \mathrm{~h}$. The interval between onset of periods of cycling was between 303 and 317 days. In group SSH, three animals exhibited a period of quiescence of between 59 and 70 days commencing between 3 December and 25 February (see Fig. 1). The interval between onset of periods of cycling in these animals was between 211 and 266 days.

Although all samples from each animal were estimated in the same assay, plasma progesterone concentrations during the second period of quiescence in the SSH group were higher than those during the first period of quiescence at the beginning of the experiment.

There was no significant effect of time of year or treatment on the preinjection prolactin concentrations (Fig. 2) as previously reported (Curlewis et al., 1986). There was a highly significant effect of time of year on the overall prolactin response to domperidone $(f=8.08, P<0.0001, d . f .=14)$ with no interaction between time of year and treatment (Fig. 2). In group SN, high concentrations of prolactin in June and July declined between September and December, rose in January to a peak in April followed by a decline by the next July. In group 
Table 1. Plasma prolactin responses (mean \pm SEM) to $1 \mathrm{mg}$ domperidone (s.c.) during periods of oestrous cyclicity and quiescence, overall, and in animals on simulated natural $(\mathrm{SN})$ and summer solstice (SSH) photoperiods

\begin{tabular}{lccccc}
\hline & $\begin{array}{c}\text { Plasma } \\
\text { prolactin } \\
\text { concentrations } \\
\left(\mathrm{ng} \mathrm{ml}^{-1}\right)\end{array}$ & $n$ & $\begin{array}{c}\text { Plasma } \\
\text { prolactin } \\
\text { Goncentrations } \\
\left(\mathrm{ng} \mathrm{ml}^{-1}\right)\end{array}$ & $n$ & $\begin{array}{c}P \text { for } \\
\text { cycling versus } \\
\text { quiescent }\end{array}$ \\
\hline $\mathrm{SN}+\mathrm{SSH}$ & $5.3 \pm 0.5$ & 104 & $14.9 \pm 0.9$ & 50 & $<0.001$ \\
$\mathrm{SN}$ & $5.7 \pm 0.7$ & 46 & $15.5 \pm 1.1$ & 26 & $<0.01$ \\
$\mathrm{SSH}$ & $5.0 \pm 0.7$ & 58 & $14.1 \pm 1.4$ & 23 & $<0.01$ \\
\hline
\end{tabular}

$n=$ Overall number of challenges in each group; $P$ values relate to differences between prolactin responses during periods of cycling and quiescence.

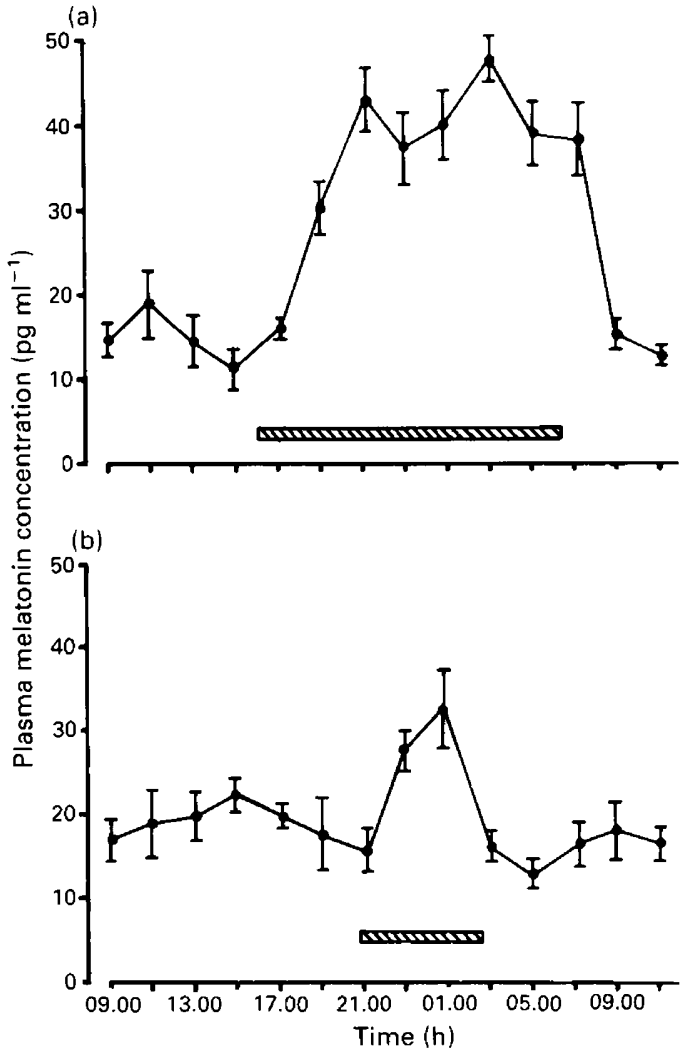

Fig. 3. Mean ( \pm SEM) concentrations of melatonin in plasma of animals held on (a) simulated natural ( $\mathrm{SN} ; n=5$ ) and (b) summer solstice hold ( $\mathrm{SSH} ; n=5$ ) photoperiods taken every $2 \mathrm{~h}$ for $26 \mathrm{~h}$ on $16-17$ December 1987. The period of darkness (SN $14 \mathrm{~h} 47 \mathrm{~min}$; SSH $5 \mathrm{~h}$ $44 \mathrm{~min}$ ) is shown by the hatched bar.

SSH, concentrations of prolactin declined in August and rose again from January to March. There was a highly significant difference between prolactin responses during cycling and quiescent periods both overall $(P<0.001)$ and within each treatment $(P<0.01)$, with an approximately threefold increase in response to domperidone during periods of quiescence (Table 1).

Plasma melatonin measured in blood samples taken every $2 \mathrm{~h}$ over $24 \mathrm{~h}$ demonstrated that melatonin secretion occurred only during the periods of darkness. Animals maintained on fixed summer solstitial photoperiods exhibited a compressed melatonin profile (Fig. 3), with high concentrations in only two samples. This contrasts with the profile for group $\mathrm{SN}$ in which concentrations were high for at least $12 \mathrm{~h}$.

\section{Discussion}

The commencement of the breeding season, approximately two months after the summer solstice, in both the simulated natural and summer solstice hold photoperiod groups is comparable with earlier studies in this species (Merchant and Calaby, 1981; Curlewis and Loudon, 1989). This was accompanied in both cases by reductions in prolactin response to domperidone that occurred spontaneously in group SSH with no reduction in photoperiod. These data support earlier studies that demonstrated that the onset of the breeding season occurs owing to refractoriness to a long photoperiod signal (Curlewis and Loudon, 1988a). In addition, data from the tammar wallaby show that pinealectomy in seasonal quiescence does not alter the time of onset of the breeding season after the summer solstice, despite an unchanging melatonin signal (McConnell and Hinds, 1985). Here, we provide evidence that reproductive long day photorefractoriness is associated with a decline in prolactin. Further evidence that a reduction in photoperiod is not necessary for onset of the breeding season comes from the observation that one animal (GL47) had begun cycling before the summer solstice. Finally, in group $\mathrm{SN}$, the onset of the second breeding season and accompanying reduction in prolactin response occurred before the time of maximum photoperiod. An explanation for this foreshortening of the annual reproductive cycle might be that we consistently overestimated the duration of the simulated natural photoperiod by adding civil twilight and thus advanced the long day photorefractory response.

In common with previous data from both the tammar and Bennett's wallaby this study demonstrates no seasonal or photoperiod-induced changes in baseline plasma prolactin values. There was, in the present study, a highly significant correlation between the transient prolactin response to domperidone and oestrous cyclicity across the whole study 
with a high response during periods of quiescence and a low response during periods of oestrous cyclicity. This result agrees with observations that the transition from the breeding season to seasonal quiescence is associated with an increase in prolactin secretion induced by a dopamine antagonist (Pearce-Kelly et al., 1992). In addition, tammars have been shown to exhibit a transient increase in plasma prolactin concentration at the time of lights-on in artificial long photoperiods (McConnell et al., 1986; Hinds, 1989). In a study of male Bennett's wallabies culled at different times of the year, Curlewis (1989) found an increase in pituitary prolactin content in summer that could provide an increased releasable pool. Taken together, these data provide strong correlative evidence for a role for prolactin in the control of seasonal quiescence, particularly as the periods of quiescence in the SSH group were not synchronous, which is reflected in the lack of clear change in the mean prolactin response after January.

We cannot explain the inability of bromocriptine to reactivate the corpus luteum in late seasonal quiescence (Tyndale-Biscoe and Hinds, 1984; Curlewis et al., 1986; Brinklow and Loudon, 1989). One possibility is that prolactin is regulated by stimulatory factor(s) at this time, in addition to an underlying inhibitory dopaminergic control. This possibility is supported by data from Hinds (1989), who found that only two out of four tammars in early seasonal quiescence responded to bromocriptine with an abolition of the dawn pulse of prolactin, which is observed in this species, and luteal reactivation.

Three out of four animals maintained on fixed summer solstitial photoperiods throughout the study reported here exhibited spontaneous changes in oestrous cyclicity and prolactin response to domperidone. Furthermore, these changes occurred despite an unchanging melatonin signal. Blood samples from animals from group SSH at the time of the winter solstice, 6 months after exposure to constant long photoperiods, exhibited a short period of high concentration of melatonin in plasma similar to that observed in earlier studies of wallabies maintained on long photoperiods (Loudon and Curlewis, 1987; Curlewis and Loudon, 1988b). In contrast, animals maintained on simulated natural photoperiods exhibited a long period of high melatonin concentration also comparable to our earlier studies (Loudon and Curlewis, 1987; Curlewis and Loudon, 1988b). Thus, in response to an invariant long photoperiod signal, three of the animals exhibited spontaneous changes in reproductive state with a period substantially shorter than one year.

These data are in contrast to those from wallabies held on winter solstitial photoperiods for the duration of the normal seasonal quiescent period (Loudon and Curlewis, 1989), from wallabies given melatonin implants that blocked the daily changing melatonin signal (Loudon and Brinklow, 1990), or pineal denervated by superior cervical ganglionectomy during the breeding season (tammar: Renfree et al., 1981). In all three cases, animals continued to cycle throughout the normal period of quiescence when a decrease in the duration of the daily melatonin signal was prevented. These studies suggest that seasonal wallabies need to experience an increase in photoperiod and associated change in melatonin signal after the winter solstice to enter seasonal quiescence. At some point after the onset of seasonal quiescence, animals develop refractoriness to a long day signal and commence the next breeding season (see Curlewis and Loudon, 1989). Spontaneous changes in reproductive state and prolactin in seasonal wallabies can apparently be expressed only when animals are exposed to long photoperiods. These spontaneous changes may be taken as evidence for an endogenous circannual rhythm. Absence of spontaneous changes of reproductive state in animals held on short photoperiods or treated with melatonin (see above) suggests an absolute photoperiodic requirement for the expression of such rhythms. It must, however, be noted that all of these studies have been conducted over relatively short periods. These data are comparable to data from red deer in which endogenous rhythms of food intake, plasma prolactin concentration and coat growth are present in hinds held on summer solstice photoperiods from birth (Brinklow and Loudon, 1990), while adult hinds treated with melatonin from mid-winter continued to exhibit repeated oestrous cycles and did not enter anoestrus (Adam et al., 1989). Sheep, in contrast, have been shown to exhibit endogenous circannual rhythms in both long and short photoperiods (Howles et al., 1982; Karsch et al., 1989).

In conclusion, we have demonstrated a clear association between periods when the prolactin response to a dopamine antagonist is low and periods of oestrous cyclicity in nonlactating female Bennett's wallabies. This study provides further evidence that prolactin is involved in the control of seasonal quiescence. In addition we have demonstrated that spontaneous changes in reproductive state and associated changes in prolactin secretion can occur in female wallabies on constant long photoperiods.

The authors would like to thank A. S. McNeilly for the gift of 33-1-8 antiserum and iodinated prolactin; J. Boyle and J. de Belin for help with blood sampling of animals and determination of hormone concentrations; and A. Beasey and the staff of the animal hospital for help with capture and management of the animals. Work was carried out under a joint MRC/AFRC programme grant and an SERC project grant held by $A$. Loudon.

\section{References}

Adam CL, Moir CE and Shiach P (1989) Melatonin can induce year round ovarian cyclicity in red deer (Cervus elaphus) Joumal of Reproduction and Fertility 87 401-408

Andrewartha HG and Barker S (1969) Introduction to a study of the ecology of the Kangaroo Island wallaby, Protemnodon eugenii (Demarest) within Flinders Chase, Kangaroo Island, South Australia Transactions of the Royal Society of South Australia 93, 127-132

Berger PJ (1966) Eleven month embryonic diapause in a marsupial Nature 211 435-436

Berger PJ and Sharman GB (1969) Progesterone induced development of dormant blastocysts in the tammar wallaby, Macropus engenii, Demarest: Marsupialia Journal of Reproduction and Fertility 20 201-210

Brinklow BR and Loudon ASI (1989) Effects of exogenous prolactin and bromocriptine on seasonal reproductive quiescence in the Bennett's wallaby (Macropus rufogriseus rufogriseus) Joumal of Endocrinology 120 189-193

Brinklow BR and Loudon ASI (1990) Development of seasonal rhythms in a long lived ungulate: the red deer (Cerous elaphus) Joumal of Interdisciplinary Cycle Research 21 173-175

Catt DC (1977) The breeding biology of the Bennett's wallaby (Macropus rufogriseus fruticus) in South Canterbury, New Zealand New Zealand Journal of Zoology 4 401-411

Curlewis JD (1989) The breeding season of the Bennett's wallaby (Macropus rufogriseus rufogriseus) in Tasmania Journal of Zoology 218 337-339

Curlewis JD and Loudon ASI (1988a) Experimental manipulations of prolactin following removal of pouch young or bromocriptine treatment during 
lactational quiescence in the Bennett's wallaby Joumal of Endocrinology 119 405-411

Curlewis ID and Loudon ASI (1988b) Effects of photoperiod on the 24-hour melatonin profites of the Bennett's wallaby (Macropus rufogriseus rufogriseus) Journal of Pineal Research 5 373-384

Curlewis JD and Loudon ASI (1989) The role of refractoriness to long daylengths in the reproductive cycle of the Bennett's wallaby (Macropus rufogriseus rufogriseus) Journal of Experimental Zoology 252 200-206

Curlewis JD, White AS, Loudon ASI and McNeilly AS (1986) Effects of lactation and season on plasma prolactin concentrations and response to bromocriptine during lactation in the Bennett's wallaby (Macropus rufogriseus rufogriseus) Joumal of Endocrinology 110 59-66

Curlewis JD, White AS and Loudon ASI (1987) The onset of seasonal quiescence in the Bennett's wallaby (Macropus rufogriseus rufogriseus) Journal of Reproduction and Fertility 80 119-124

Davis DE (1976) Hibernation and circannual rhythms of food consumption in marmots and ground squirrels Quarterly Review of Biology 51 477-515

Fleming D, Cinderey RN and Hearn JP (1983) The reproductive biology of the Bennett's wallaby (Macropus rufogriseus rufogriseus) ranging free at Whipsnade Park Journal of Zoology 201 283-291

Flint APF and Renfree MB (1982) Oestradiol $17-\beta$ in the circulation during seasonal reactivation of the diapausing blastocyst in a wild population of tammar wallabies (Macropus eugenii) Journal of Endocrinology 95 293-300

Goodman RL and Karsch FJ (1981) The hypothalamic pulse generator: a key determinant of reproductive cycles in sheep. In Biological Clocks in Seasonal Reproductive Cycles pp 223-236 Ed. BK and DE Follett. Wright, Bristol

Hearn JP (1974) The pituitary gland and implantation in the tammar wallaby (Macropus engenii) Joumal of Reproduction and Fertility 39 235-241

Helwig JT and Council KA (1979) SAS User's Guide SAS Institute Inc., Cary, NC

Hinds LA (1989) Morning pulse of prolactin maintains seasonal quiescence in the tammar, Macropus eugenii Journal of Reproduction and Fertility 87 735-744

Horn CA, Fletcher TB and Carpenter S (1985) Effects of oestradiol-17 $\beta$ on peripheral plasma concentrations of LH and FSH in ovariectomized tammars (Macropus eugenii) Joumal of Reproduction and Fertility 73 585-592

Howles CM, Craighton I and Haynes NB (1982) Long term testicular volume and plasma prolactin in rams reared for three years in constant photoperiod Jourmal of Reproduction and Fertility 65 439-446

Karsch FJ, Robinson JE, Woodfill CJI and Brown MB (1989) Circannual cycles of $\mathrm{LH}$ and prolactin secretion in ewes during prolonged exposure to a fixed photoperiod: evidence for an endogenous reproductive rhythm Biology of Reproduction 41 1034-1046

Loudon ASI and Brinklow BR (1990) Melatonin implants prevent the onset of seasonal quiescence and suppress the release of prolactin in response to a dopamine antagonist in the Bennett's wallaby (Macropus rufogriseus rufogriseus) Journal of Reproduction and Fertility $90611-618$
Loudon ASI and Curlewis JD (1987) Refractoriness to melatonin and short daylengths in early seasonal quiescence in the Bennett's wallaby (Macropus rufogriseus rufogriseus) Journal of Reproduction and Fertility 81 543-552

Loudon ASI and Curlewis JD (1989) Evidence that the seasonally breeding Bennett's wallaby (Macropus rufogriseus rufogriseus) does not exhibit short-day photorefractoriness Journal of Reproduction and Fertility 87 641-648

McConnell SJ and Hinds LA (1985) Effect of pinealectomy on plasma melatonin prolactin and progesterone concentrations during seasonal reproductive quiescence in the tammar (Macropus engenii) Journal of Reproduction and Fertility 75 433-440

McConnell SJ, Tyndale-Biscoe CH and Hinds LA (1986) Change in duration of elevated concentrations of melatonin is the major factor in the photoperiod response of the tammar (Macropus eugenii) Journal of Reproduction and Fertility $77623-632$

McNeilly AS and Friesen HG (1978) Heterologous radioimmunoassay for rabbit prolactin Endocrinology 107 1543-1547

Merchant JC and Calaby JH (1981) Reproductive biology of the red-necked wallaby (Macropus rufogriseus banksianus) and Bennett's wallaby (Macropus rufogriseus rufogriseus) Jourmal of Zoology 194 203-217

Pearce-Kelly AS, Loudon ASI and Curlewis ID (1992) Seasonal and lactational effects on the prolactin response to a dopamine antagonist and TRH in the Bennett's wallaby (Macropus rufogriseus rufogriseus) General and Comparative Endocrinology 86 323-331

Renfree MB (1979) Initiation of development of diapausing embryo by mammary denervation during lactation in a marsupial Nature 278 549-551

Renfree MB, Lincoln DW, Almeida OFX and Short RV (1981) Abolition of seasonal embryonic diapause in a wallaby by pineal denervation Nature 293 138-139

Renfree MB, Wallace GI and Young IR (1982) Effects of progesterone, oestradiol-17 $\beta$ and androstenedione on follicular growth after removal of the corpus luteum during lactational and seasonal quiescence in the tammar wallaby Journal of Endocrinology 92 397-403

Tyndale-Biscoe CH and Hawkins J (1977) The corpora lutea of marsupials, aspects of function and control. In Reproduction and Evolution pp 245-252 Ed. JH Calaby and CH Tyndale-Biscoe. Australian Academy of Science, Canberra

Tyndale-Biscoe CH and Hinds LA (1984) Seasonal patterns of circulating progesterone and prolactin and response to bromocriptine in the female tammar wallaby (Macropus eugenii) General and Comparative Endocrinology 53 $58-68$

Tyndale-Biscoe CH, Hinds L and McConnell SJ (1986) Seasonal breeding in a marsupial: opportunities of a new species for an old problem Recent Progress in Hormone Research 42 471-512

Webley GE, Mehl H and Willey KP (1985) Validation of a sensitive direct assay for melatonin for investigation of circadian rhythms in different species Joumal of Endocrinology 106 387-394 